\title{
Positive solutions of nonlinear boundary value problems for delayed fractional $q$-difference systems
}

\section{Qiaozhen Yuan and Wengui Yang*}

"Correspondence:

wgyang0617@yahoo.com Ministry of Public Education,

Sanmenxia Polytechnic, Sanmenxia, Henan 472000, China

\begin{abstract}
In this paper, we investigate the existence and uniqueness of positive solutions to nonlinear boundary value problems for delayed fractional $q$-difference systems by applying the properties of the Green function and some well-known fixed-point theorems. As applications, some examples are presented to illustrate the main results. MSC: 39A13; 34B18; 34A08

Keywords: fractional q-difference systems; boundary value problems; positive solutions; fixed-point theorems
\end{abstract}

\section{Introduction}

In the past decades, fractional differential equations have been proved to be valuable tools in the investigation of many phenomena in various fields of science and engineering such as physics, mechanics, chemistry, biology, engineering, etc. Therefore, the subject of fractional differential equations has gained considerable attention by many researchers. Some recent results on fractional boundary value problems can be found in [1-4] and references therein. For example, Ahmad and Nieto [5] dealt with some existence results for a boundary value problem involving a nonlinear fractional order integrodifferential equation with integral boundary conditions based on a contraction mapping principle and Krasnoselskiii's fixed-point theorem. Ahmad et al. [6] investigated the existence and uniqueness of solutions for a class of Caputo-type fractional boundary value problems involving four-point nonlocal Riemann-Liouville integral boundary conditions of different order by means of standard tools of fixed-point theory and Leray-Schauder nonlinear alternative. Ouyang et al. [7] considered the following nonlinear system of fractional order differential equations with delays:

$$
\begin{aligned}
& \left(D^{\alpha_{i}} u_{i}\right)(t)+f_{i}\left(t, u_{1}\left(\tau_{i 1}(t)\right), \ldots, u_{N}\left(\tau_{i N}(t)\right)\right)=0, \quad 0<t<1, \\
& u_{i}^{(j)}(0)=0, \quad j=0,1, \ldots, n_{i}-2, i=1,2, \ldots, N, \\
& u_{i}^{\left(n_{i}-1\right)}(1)=\eta_{i}, \quad i=1,2, \ldots, N,
\end{aligned}
$$

where $D^{\alpha_{i}}$ is the standard Riemann-Liouville fractional derivative. By using some fixedpoint theorems and some properties of the Green function, the existence of positive solutions was obtained.

@2014 Yuan and Yang; licensee Springer. This is an Open Access article distributed under the terms of the Creative Commons Attribution License (http://creativecommons.org/licenses/by/2.0), which permits unrestricted use, distribution, and reproduction in any medium, provided the original work is properly cited. 
The $q$-difference calculus or quantum calculus is an old subject that was initially developed by Jackson $[8,9]$; basic definitions and properties of $q$-difference calculus can be found in the book mentioned in [10].

The fractional $q$-difference calculus had its origin in the works by Al-Salam [11] and Agarwal [12]. Recently, maybe due to the explosion in research within the fractional differential calculus setting, new developments in this theory of fractional $q$-difference calculus were made; for example, $q$-analogues of the integral and differential fractional operators properties such as the $q$-Laplace transform, $q$-Taylor's formula, Mittage-Leffler function [13-16], just to mention some.

More recently, boundary value problems of nonlinear fractional $q$-difference equations have gained popularity and importance. Many researchers pay attention to the existence and multiplicity of solutions or positive solutions for nonlinear boundary value problems of fractional $q$-difference equations by means of upper and lower solutions method and some fixed-point theorems such as the Krasnoselskii fixed-point theorem, the LeggettWilliams fixed-point theorem, and the Schauder fixed-point theorem; for examples, see [17-21] and the references therein. El-Shahed and Al-Askar [22] studied the existence of multiple positive solutions to the nonlinear $q$-fractional boundary value problems by using Guo-Krasnoselskii's fixed-point theorem in a cone. Graef and Kong [23] investigated the uniqueness, existence, and nonexistence of positive solutions for the boundary value problem with fractional $q$-derivatives in terms of different ranges of $\lambda$. Ma and Yang [24] obtained the existence of solutions for multi-point boundary value problems of nonlinear fractional $q$-difference equations by means of the Banach contraction principle and Krasnoselskii's fixed-point theorem. Zhao et al. [25] showed some existence results of positive solutions to nonlocal $q$-integral boundary value problems of a nonlinear fractional $q$-derivative equation using the generalized Banach contraction principle, the monotone iterative method, and Krasnoselskii's fixed-point theorem. Ferreira [26] and [27] dealt with the existence of positive solutions to nonlinear $q$-difference boundary value problems,

$$
\begin{aligned}
& \left(D_{q}^{\alpha} u\right)(t)=-f(t, u(t)), \quad 0 \leq t \leq 1,1<\alpha \leq 2, \\
& u(0)=u(1)=0
\end{aligned}
$$

and

$$
\begin{array}{ll}
\left(D_{q}^{\alpha} u\right)(t)=-f(t, u(t)), & 0 \leq t \leq 1,2<\alpha \leq 3, \\
u(0)=\left(D_{q} u\right)(0)=0, & \left(D_{q} u\right)(1)=\beta \geq 0,
\end{array}
$$

respectively. By applying a fixed-point theorem in cones, sufficient conditions for the existence of nontrivial solutions were enunciated.

In [28], Liang and Zhang discussed the following nonlinear $q$-fractional three-point boundary value problem:

$$
\begin{aligned}
& \left(D_{q}^{\alpha} u\right)(t)+f(t, u(t))=0, \quad t \in[0,1], \alpha \in(2,3], \\
& u(0)=\left(D_{q} u\right)(0)=0, \quad\left(D_{q} u\right)(1)=\beta\left(D_{q} u\right)(\eta) .
\end{aligned}
$$


By using a fixed-point theorem in partially ordered sets, the authors obtained sufficient conditions for the existence and uniqueness of positive and nondecreasing solutions to the above boundary value problem.

In [29], Ahmad et al. studied the following nonlocal boundary value problems of nonlinear fractional $q$-difference equations,

$$
\begin{aligned}
& \left({ }^{c} D_{q}^{\alpha} u\right)(t)=f(t, u(t)), \quad t \in[0,1], \alpha \in(1,2], \\
& a_{1} u(0)-b_{1}\left(D_{q} u\right)(0)=c_{1} u\left(\eta_{1}\right), \quad a_{2} u(1)+b_{2}\left(D_{q} u\right)(1)=c_{2} u\left(\eta_{2}\right),
\end{aligned}
$$

where ${ }^{c} D_{q}^{\alpha}$ denotes the Caputo fractional $q$-derivative of order $\alpha$, and $a_{i}, b_{i}, c_{i}, \eta_{i} \in \mathbb{R}(i=$ $1,2)$. The existence of solutions for the problem was shown by applying some well-known tools of fixed-point theory, such as Banach contraction principle, Krasnoselskii's fixedpoint theorem, and Leray-Schauder nonlinear alternative.

In [30], Alsaedi et al. were concerned with the following nonlinear fractional $q$ difference equations with nonlocal integral boundary conditions:

$$
\begin{aligned}
& \left({ }^{c} D_{q}^{\beta} u\right)(t)+\lambda u(t)=f(t, u(t)), \quad t \in[0,1], \beta \in(1,2], \\
& u(0)=0, \quad u(1)=\left(I_{q} u\right)(\eta)=\int_{0}^{\eta} u(s) d_{q} s, \quad 0<\eta<1 .
\end{aligned}
$$

The existence results were obtained by applying some well-known fixed-point theorems.

Motivated by the above works, in this paper, we consider the following system of nonlinear fractional $q$-difference equations with delays:

$$
\begin{aligned}
& \left(D_{q}^{\alpha_{i}} u_{i}\right)(t)+f_{i}\left(t, u_{1}\left(\tau_{i 1}(t)\right), \ldots, u_{N}\left(\tau_{i N}(t)\right)\right)=0, \quad 0<t<1, \\
& \left(D_{q}^{j} u_{i}\right)(0)=0, \quad j=0,1, \ldots, n_{i}-2, i=1,2, \ldots, N, \\
& \left(D_{q}^{n_{i}-1} u_{i}\right)(1)=\eta_{i}, \quad i=1,2, \ldots, N,
\end{aligned}
$$

where $D_{q}^{\alpha_{i}}$ is the fractional $q$-derivative of the Riemann-Liouville type, $\alpha_{i} \in\left(n_{i}-1, n_{i}\right]$ for some $n_{i}>2, \eta_{i} \geq 0$ for $i=1,2, \ldots, N, 0 \leq \tau_{i j}(t) \leq t$ for $i, j=1,2, \ldots, N$, and $f_{i}$ is a nonlinear function from $[0,1] \times \mathbb{R}_{+}^{N}$ to $\mathbb{R}_{+}=[0, \infty)$. The purpose of this paper is to establish sufficient conditions on the existence of positive solutions for fractional $q$-difference system (1.1) by using some properties of the Green function and some fixed-point theorems such as the Banach contraction principle, Krasnoselskii's fixed-point theorem, and the LeraySchauder nonlinear alternative. By a positive solution for the fractional $q$-difference system $(1.1)$ we mean a mapping with positive components on $[0,1]$ such that $(1.1)$ is satisfied. Obviously, (1.1) includes the usual system of fractional $q$-difference equations when $\tau_{i j}(t) \equiv t$ for all $i$ and $j$. Therefore, the obtained results generalize and include some existing ones.

\section{Preliminaries}

For convenience of the reader, we present some necessary definitions and lemmas of fractional $q$-calculus theory to facilitate analysis of problem (1.1). These details can be found in the recent literature; see [10] and references therein. 
Let $q \in(0,1)$ and define

$$
[a]_{q}=\frac{q^{a}-1}{q-1}, \quad a \in \mathbb{R}
$$

The $q$-analogue of the power $(a-b)^{n}$ with $n \in \mathbb{N}_{0}$ is

$$
(a-b)^{(0)}=1, \quad(a-b)^{(n)}=\prod_{k=0}^{n-1}\left(a-b q^{k}\right), \quad n \in \mathbb{N}, a, b \in \mathbb{R} .
$$

More generally, if $\alpha \in \mathbb{R}$, then

$$
(a-b)^{(\alpha)}=a^{\alpha} \prod_{n=0}^{\infty} \frac{a-b q^{n}}{a-b q^{\alpha+n}} .
$$

Note that, if $b=0$, then $a^{(\alpha)}=a^{\alpha}$. The $q$-gamma function is defined by

$$
\Gamma_{q}(x)=\frac{(1-q)^{(x-1)}}{(1-q)^{x-1}}, \quad x \in \mathbb{R} \backslash\{0,-1,-2, \ldots\},
$$

and satisfies $\Gamma_{q}(x+1)=[x]_{q} \Gamma_{q}(x)$.

The $q$-derivative of a function $f$ is here defined by

$$
\left(D_{q} f\right)(x)=\frac{f(x)-f(q x)}{(1-q) x}, \quad\left(D_{q} f\right)(0)=\lim _{x \rightarrow 0}\left(D_{q} f\right)(x),
$$

and $q$-derivatives of higher order by

$$
\left(D_{q}^{0} f\right)(x)=f(x) \quad \text { and } \quad\left(D_{q}^{n} f\right)(x)=D_{q}\left(D_{q}^{n-1} f\right)(x), \quad n \in \mathbb{N} .
$$

The $q$-integral of a function $f$ defined in the interval $[0, b]$ is given by

$$
\left(I_{q} f\right)(x)=\int_{0}^{x} f(t) d_{q} t=x(1-q) \sum_{n=0}^{\infty} f\left(x q^{n}\right) q^{n}, \quad x \in[0, b] .
$$

If $a \in[0, b]$ and $f$ is defined in the interval $[0, b]$, its integral from $a$ to $b$ is defined by

$$
\int_{a}^{b} f(t) d_{q} t=\int_{0}^{b} f(t) d_{q} t-\int_{0}^{a} f(t) d_{q} t
$$

Similarly to what is done for derivatives, an operator $I_{q}^{n}$ can be defined, namely,

$$
\left(I_{q}^{0} f\right)(x)=f(x) \quad \text { and } \quad\left(I_{q}^{n} f\right)(x)=I_{q}\left(I_{q}^{n-1} f\right)(x), \quad n \in \mathbb{N} .
$$

The fundamental theorem of calculus applies to these operators $I_{q}$ and $D_{q}$, i.e.,

$$
\left(D_{q} I_{q} f\right)(x)=f(x),
$$


and if $f$ is continuous at $x=0$, then

$$
\left(I_{q} D_{q} f\right)(x)=f(x)-f(0) .
$$

Basic properties of the two operators can be found in the book [10]. We now point out three formulas that will be used later $\left({ }_{i} D_{q}\right.$ denotes the derivative with respect to variable $\left.i\right)$

$$
\begin{aligned}
& {[a(t-s)]^{(\alpha)}=a^{\alpha}(t-s)^{(\alpha)}, \quad{ }_{t} D_{q}(t-s)^{(\alpha)}=[\alpha]_{q}(t-s)^{(\alpha-1)},} \\
& \left({ }_{x} D_{q} \int_{0}^{x} f(x, t) d_{q} t\right)(x)=\int_{0}^{x}{ }_{x} D_{q} f(x, t) d_{q} t+f(q x, x) .
\end{aligned}
$$

We note that if $\alpha>0$ and $a \leq b \leq t$, then $(t-a)^{(\alpha)} \geq(t-b)^{(\alpha)}[26]$.

Definition 2.1 ([12]) Let $\alpha \geq 0$ and $f$ be function defined on $[0,1]$. The fractional $q$ integral of the Riemann-Liouville type is $I_{q}^{0} f(x)=f(x)$ and

$$
\left(I_{q}^{\alpha} f\right)(x)=\frac{1}{\Gamma_{q}(\alpha)} \int_{0}^{x}(x-q t)^{(\alpha-1)} f(t) d_{q} t, \quad \alpha>0, x \in[0,1] .
$$

Definition 2.2 ([14]) The fractional $q$-derivative of the Riemann-Liouville type of order $\alpha \geq 0$ is defined by $D_{q}^{0} f(x)=f(x)$ and

$$
\left(D_{q}^{\alpha} f\right)(x)=\left(D_{q}^{m} I_{q}^{m-\alpha} f\right)(x), \quad \alpha>0,
$$

where $m$ is the smallest integer greater than or equal to $\alpha$.

Definition 2.3 ([14]) The fractional $q$-derivative of the Caputo type of order $\alpha \geq 0$ is defined by

$$
\left({ }^{c} D_{q}^{\alpha} f\right)(x)=\left(I_{q}^{m-\alpha} D_{q}^{m} f\right)(x), \quad \alpha>0,
$$

where $m$ is the smallest integer greater than or equal to $\alpha$.

Lemma 2.4 ([12,15]) Let $\alpha, \beta \geq 0$ and $f$ be a function defined on $[0,1]$. Then the following formulas hold:

(1) $\left(I_{q}^{\beta} I_{q}^{\alpha} f\right)(x)=I_{q}^{\alpha+\beta} f(x)$,

(2) $\left(D_{q}^{\alpha} I_{q}^{\alpha} f\right)(x)=f(x)$

Theorem 2.5 ([26]) Let $\alpha>0$ and $p$ be a positive integer. Then the following equality holds:

$$
\left(I_{q}^{\alpha} D_{q}^{\alpha} f\right)(x)=\left(D_{q}^{\alpha} I_{q}^{\alpha} f\right)(x)-\sum_{k=0}^{p-1} \frac{x^{\alpha-p+k}}{\Gamma_{q}(\alpha+k-p+1)}\left(D_{q}^{k} f\right)(0) .
$$

Theorem 2.6 (Banach contraction mapping theorem [31]) Let $M$ be a complete metric space and let $T: M \rightarrow M$ be a contraction mapping. Then $T$ has a unique fixed point. 
Theorem $2.7([32,33])$ Let $C$ be a closed and convex subset of a Banach space X. Assume that $U$ is a relatively open subset of $C$ with $0 \in U$ and $T: \bar{U} \rightarrow C$ is completely continuous. Then at least one of the following two properties holds:

(i) $T$ has a fixed point in $\bar{U}$,

(ii) there exist $u \in \partial U$ and $\lambda \in(0,1)$ with $u=\lambda T u$.

Theorem 2.8 (Krasnoselskii fixed-point theorem [31,34]) Let $P$ be a cone in a Banach space $X$. Assume that $\Omega_{1}$ and $\Omega_{2}$ are open subsets of $X$ with $0 \in \Omega_{1}$ and $\bar{\Omega}_{1} \subseteq \Omega_{2}$. Suppose that $T: P \cap\left(\bar{\Omega}_{2} \backslash \Omega_{1}\right)$ is a completely continuous operator such that either

(i) $\|T u\| \leq\|u\|$ for $u \in P \cap \partial \Omega_{1}$ and $\|T u\| \geq\|u\|$ for $u \in P \cap \partial \Omega_{2}$, or

(ii) $\|T u\| \geq\|u\|$ for $u \in P \cap \partial \Omega_{1}$ and $\|T u\| \leq\|u\|$ for $u \in P \cap \partial \Omega_{2}$.

Then $T$ has a fixed point in $\bar{\Omega}_{2} \backslash \Omega_{1}$.

\section{Existence of positive solutions}

Throughout this paper, we let $E=C\left([0,1], \mathbb{R}^{N}\right)$. Then $\left(E,\|\cdot\|_{E}\right)$ is a Banach space, where

$$
\|u\|_{E}=\max _{1 \leq i \leq N} \max _{0 \leq t \leq 1}\left|u_{i}(t)\right| \quad \text { for } u=\left(u_{1}, \ldots, u_{N}\right)^{T} \in E .
$$

In this section, we always assume that $f=\left(f_{1}, \ldots, f_{N}\right)^{T} \in C\left([0,1] \times \mathbb{R}_{+}^{N}, \mathbb{R}_{+}^{N}\right)$.

Lemma 3.1 Fractional q-difference systems (1.1) is equivalent to the following system of q-integral equations:

$$
u_{i}(t)=\int_{0}^{1} G_{i}(t, q s) f_{i}\left(s, u_{1}\left(\tau_{i 1}(s)\right), \ldots, u_{N}\left(\tau_{i N}(s)\right)\right) d_{q} s+\frac{\eta_{i} t^{\alpha_{i}-1}}{\left[\alpha_{i}-1\right]_{q} \cdots\left[\alpha_{i}-n_{i}+1\right]_{q}}
$$

for $i=1,2, \ldots, N$, where

$$
G_{i}(t, s)=\frac{1}{\Gamma_{q}\left(\alpha_{i}\right)} \begin{cases}t^{\alpha_{i}-1}(1-s)^{\left(\alpha_{i}-n_{i}\right)}-(t-s)^{\left(\alpha_{i}-1\right)}, & 0 \leq s \leq t \leq 1 \\ t^{\alpha_{i}-1}(1-s)^{\left(\alpha_{i}-n_{i}\right)}, & 0 \leq t \leq s \leq 1\end{cases}
$$

Proof It is easy to see that if $\left(u_{1}, u_{2}, \ldots, u_{N}\right)^{T}$ satisfies (3.1), then it also satisfies (1.1). So, assume that $\left(u_{1}, u_{2}, \ldots, u_{N}\right)^{T}$ is a solution to (1.1). In view of Lemma 2.4 and Theorem 2.5, integrating both sides of the first equation of (1.1) of order $\alpha_{i}$ with respect to $t$, we can see that

$$
\begin{aligned}
u_{i}(t)= & -\frac{1}{\Gamma_{q}\left(\alpha_{i}\right)} \int_{0}^{t}(t-q s)^{\left(\alpha_{i}-1\right)} f_{i}\left(s, u_{1}\left(\tau_{i 1}(s)\right), \ldots, u_{N}\left(\tau_{i N}(s)\right)\right) d_{q} s \\
& +c_{1 i} t^{\alpha_{i}-1}+c_{2 i} t^{\alpha_{i}-2}+\cdots+c_{n_{i}} t^{\alpha_{i}-n_{i}}
\end{aligned}
$$

for $0 \leq t \leq 1, i=1,2, \ldots, N$. It follows that

$$
\begin{aligned}
\left(D_{q} u_{i}\right)(t)= & -\frac{\left[\alpha_{i}-1\right]_{q}}{\Gamma_{q}\left(\alpha_{i}\right)} \int_{0}^{t}(t-q s)^{\left(\alpha_{i}-2\right)} f_{i}\left(s, u_{1}\left(\tau_{i 1}(s)\right), \ldots, u_{N}\left(\tau_{i N}(s)\right)\right) d_{q} s \\
& +\left[\alpha_{i}-1\right]_{q} c_{1 i} t^{\alpha_{i}-2}+\left[\alpha_{i}-2\right]_{q} c_{2 i} t^{\alpha_{i}-3}+\cdots+\left[\alpha_{i}-n_{i}+1\right]_{q} c_{n_{i}-1, i} t^{\alpha_{i}-n_{i}}
\end{aligned}
$$


for $0 \leq t \leq 1, i=1,2, \ldots, N$. Combining with the boundary conditions in (1.1), this yields

$$
c_{n_{i}-1, i}=0, \quad i=1,2, \ldots, N
$$

Similarly, one can obtain $c_{n_{i}-2, i}=c_{n_{i}-3, i}=\cdots=c_{2, i}=0, i=1,2, \ldots, N$. Also we have

$$
\begin{aligned}
\left(D_{q}^{n_{i}-1} u_{i}\right)(t)= & -\frac{\left[\alpha_{i}-1\right]_{q} \cdots\left[\alpha_{i}-n_{i}+1\right]_{q}}{\Gamma_{q}\left(\alpha_{i}\right)} \\
& \times \int_{0}^{t}(t-q s)^{\left(\alpha_{i}-n_{i}\right)} f_{i}\left(s, u_{1}\left(\tau_{i 1}(s)\right), \ldots, u_{N}\left(\tau_{i N}(s)\right)\right) d_{q} s \\
& +\left[\alpha_{i}-1\right]_{q} \cdots\left[\alpha_{i}-n_{i}+1\right]_{q} c_{1 i} t^{\alpha_{i}-2}, \quad i=1,2, \ldots, N .
\end{aligned}
$$

Then it follows from (3.3) and the boundary condition $\left(D_{q}^{n_{i}-1} u\right)(1)=\eta_{i}$ that

$$
\begin{aligned}
c_{1 i}= & \frac{\eta_{i}}{\left[\alpha_{i}-1\right]_{q} \cdots\left[\alpha_{i}-n_{i}+1\right]_{q}} \\
& +\frac{1}{\Gamma_{q}\left(\alpha_{i}\right)} \int_{0}^{1}(1-q s)^{\left(\alpha_{i}-n_{i}\right)} f_{i}\left(s, u_{1}\left(\tau_{i 1}(s)\right), \ldots, u_{N}\left(\tau_{i N}(s)\right)\right) d_{q} s .
\end{aligned}
$$

Therefore, for $i=1,2, \ldots, N$,

$$
\begin{aligned}
u_{i}(t)= & -\frac{1}{\Gamma_{q}\left(\alpha_{i}\right)} \int_{0}^{t}(t-q s)^{\left(\alpha_{i}-1\right)} f_{i}\left(s, u_{1}\left(\tau_{i 1}(s)\right), \ldots, u_{N}\left(\tau_{i N}(s)\right)\right) d_{q} s \\
& +\frac{\eta_{i} t^{\alpha_{i}-1}}{\left[\alpha_{i}-1\right]_{q} \cdots\left[\alpha_{i}-n_{i}+1\right]_{q}} \\
& +\frac{t^{\alpha_{i}-1}}{\Gamma_{q}\left(\alpha_{i}\right)} \int_{0}^{1}(1-q s)^{\left(\alpha_{i}-n_{i}\right)} f_{i}\left(s, u_{1}\left(\tau_{i 1}(s)\right), \ldots, u_{N}\left(\tau_{i N}(s)\right)\right) d_{q} s \\
= & \frac{1}{\Gamma_{q}\left(\alpha_{i}\right)} \int_{0}^{t}\left(t^{\alpha_{i}-1}(1-q s)^{\left(\alpha_{i}-n_{i}\right)}-(t-q s)^{\left(\alpha_{i}-1\right)}\right) f_{i}\left(s, u_{1}\left(\tau_{i 1}(s)\right), \ldots, u_{N}\left(\tau_{i N}(s)\right)\right) d_{q} s \\
& +\frac{1}{\Gamma_{q}\left(\alpha_{i}\right)} \int_{0}^{1} t^{\alpha_{i}-1}(1-q s)^{\left(\alpha_{i}-n_{i}\right)} f_{i}\left(s, u_{1}\left(\tau_{i 1}(s)\right), \ldots, u_{N}\left(\tau_{i N}(s)\right)\right) d_{q} s \\
& +\frac{\eta_{i} t^{\alpha_{i}-1}}{\left[\alpha_{i}-1\right]_{q} \cdots\left[\alpha_{i}-n_{i}+1\right]_{q}} \\
= & \int_{0}^{1} G_{i}(t, q s) f_{i}\left(s, u_{1}\left(\tau_{i 1}(s)\right), \ldots, u_{N}\left(\tau_{i N}(s)\right)\right) d_{q} s+\frac{\eta_{i} t^{\alpha_{i}-1}}{\left[\alpha_{i}-1\right]_{q} \cdots\left[\alpha_{i}-n_{i}+1\right]_{q}}
\end{aligned}
$$

where $G_{i}$ is defined as in (3.2). The proof is completed.

Some properties of the Green functions $G_{i}(t, s)$ needed in the sequel are now stated and proved.

Lemma 3.2 Function $G_{i}(t, s)$ defined above satisfies the following conditions:

(a) $G_{i}(t, q s) \geq 0$ and $G_{i}(t, q s) \leq G_{i}(1, q s)$ for all $0 \leq t, s \leq 1$;

(b) $G_{i}(t, q s) \geq g_{i}(t) G_{i}(1, q s)$ for all $0 \leq t, s \leq 1$ with $g(t)=t^{\alpha_{i}-1}$. 
Proof We start by defining the two functions

$$
\varphi_{i}(t, s)=t^{\alpha_{i}-1}(1-s)^{\left(\alpha_{i}-n_{i}\right)}-(t-s)^{\left(\alpha_{i}-1\right)}, \quad 0 \leq s \leq t \leq 1,
$$

and

$$
\psi_{i}(t, s)=t^{\alpha_{i}-1}(1-s)^{\left(\alpha_{i}-n_{i}\right)}, \quad 0 \leq t \leq s \leq 1 .
$$

It is clear that $\psi_{i}(t, q s) \geq 0$ and $\psi_{i}(0, q s)=0$. On the other hand, for $t \neq 0$

$$
\begin{aligned}
\varphi_{i}(t, q s) & =t^{\alpha_{i}-1}(1-q s)^{\left(\alpha_{i}-n_{i}\right)}-t^{\alpha_{i}-1}\left(1-q \frac{s}{t}\right)^{\left(\alpha_{i}-1\right)} \\
& \geq t^{\alpha_{i}-1}\left((1-q s)^{\left(\alpha_{i}-n_{i}\right)}-(1-q s)^{\left(\alpha_{i}-1\right)}\right) \geq 0 .
\end{aligned}
$$

Therefore, $G_{i}(t, q s) \geq 0$. Moreover, for fixed $s \in[0,1]$,

$$
\begin{aligned}
t D_{q} \varphi_{i}(t, q s) & =\left[\alpha_{i}-1\right]_{q} t^{\alpha_{i}-2}(1-q s)^{\left(\alpha_{i}-n_{i}\right)}-\left[\alpha_{i}-1\right]_{q}(t-q s)^{\left(\alpha_{i}-2\right)} \\
& \geq\left[\alpha_{i}-1\right]_{q} t^{\alpha_{i}-2}(1-q s)^{\left(\alpha_{i}-n_{i}\right)}-\left[\alpha_{i}-1\right]_{q} t^{\left(\alpha_{i}-2\right)}\left(1-q \frac{s}{t}\right)^{\left(\alpha_{i}-2\right)} \\
& \geq\left[\alpha_{i}-1\right]_{q} t^{\alpha_{i}-2}\left((1-q s)^{\left(\alpha_{i}-n_{i}\right)}-(1-q s)^{\left(\alpha_{i}-2\right)}\right) \geq 0,
\end{aligned}
$$

i.e., $\varphi_{i}(t, q s)$ is an increasing function of $t$. Obviously, $\psi_{i}(t, q s)$ is increasing in $t$, therefore $G_{i}(t, q s)$ is an increasing function of $t$ for fixed $s \in[0,1]$. This concludes the proof of (a).

Suppose now that $t \geq q$ s. Then we have

$$
\begin{aligned}
\frac{G_{i}(t, q s)}{G_{i}(1, q s)} & =\frac{t^{\alpha_{i}-1}(1-q s)^{\left(\alpha_{i}-n_{i}\right)}-(t-q s)^{\left(\alpha_{i}-1\right)}}{(1-q s)^{\left(\alpha_{i}-n_{i}\right)}-(1-q s)^{\left(\alpha_{i}-1\right)}} \\
& =\frac{t^{\alpha_{i}-1}\left((1-q s)^{\left(\alpha_{i}-n_{i}\right)}-\left(1-q \frac{s}{t}\right)^{\left(\alpha_{i}-1\right)}\right)}{(1-q S)^{\left(\alpha_{i}-n_{i}\right)}-(1-q S)^{\left(\alpha_{i}-1\right)}} \\
& \geq \frac{t^{\alpha_{i}-1}\left((1-q s)^{\left(\alpha_{i}-n_{i}\right)}-(1-q s)^{\left(\alpha_{i}-1\right)}\right)}{(1-q S)^{\left(\alpha_{i}-n_{i}\right)}-(1-q s)^{\left(\alpha_{i}-1\right)}}=t^{\alpha_{i}-1} .
\end{aligned}
$$

On the other hand, if $t \leq q s$, then we have

$$
\frac{G_{i}(t, q s)}{G_{i}(1, q s)}=t^{\alpha_{i}-1}
$$

and this finishes the proof of $(b)$.

Now, we are ready to present the main results.

Theorem 3.3 Suppose that there exist functions $\lambda_{i j}(t) \in C\left([0,1], \mathbb{R}_{+}\right), i, j=1,2, \ldots, N$, such that

$$
\left|f_{i}\left(t, u_{1}, \ldots, u_{N}\right)-f_{i}\left(t, v_{1}, \ldots, v_{N}\right)\right| \leq \sum_{j=1}^{N} \lambda_{i j}(t)\left|u_{j}-v_{j}\right|
$$


for $t \in[0,1],\left(u_{1}, u_{2}, \ldots, u_{N}\right)^{T},\left(v_{1}, v_{2}, \ldots, v_{N}\right)^{T} \in \mathbb{R}_{+}^{N}$. If

$$
\max _{1 \leq i \leq N} \int_{0}^{1} G_{i}(1, q s)\left(\sum_{j=1}^{N} \lambda_{i j}(s)\right) d_{q} s<1,
$$

then (1.1) has a unique positive solution.

Proof Let

$$
\Omega=\left\{u \in E \mid u_{i}(t) \geq 0 \text { for } t \in[0,1], i=1,2, \ldots, N\right\} .
$$

It is easy to see that $\Omega$ is a complete metric space. Define an operator $T$ on $\Omega$ by

$$
\begin{aligned}
\operatorname{Tu}(t)= & \int_{0}^{1} G(t, q s) f(s) d_{q} s \\
& +\operatorname{diag}\left(\frac{\eta_{1} t^{\alpha_{1}-1}}{\left[\alpha_{1}-1\right]_{q} \cdots\left[\alpha_{1}-n_{1}+1\right]_{q}}, \ldots, \frac{\eta_{N} t^{\alpha_{N}-1}}{\left[\alpha_{N}-1\right]_{q} \cdots\left[\alpha_{N}-n_{N}+1\right]_{q}}\right),
\end{aligned}
$$

where $G(t, s)=\operatorname{diag}\left(G_{1}(t, s), G_{2}(t, s), \ldots, G_{N}(t, s)\right)$ and

$$
f(t)=\left(\begin{array}{c}
f_{1}\left(t, u_{1}\left(\tau_{11}(t)\right), \ldots, u_{N}\left(\tau_{1 N}(t)\right)\right) \\
f_{2}\left(t, u_{1}\left(\tau_{21}(t)\right), \ldots, u_{N}\left(\tau_{2 N}(t)\right)\right) \\
\vdots \\
f_{N}\left(t, u_{1}\left(\tau_{N 1}(t)\right), \ldots, u_{N}\left(\tau_{N N}(t)\right)\right)
\end{array}\right)
$$

Because of the continuity of $G$ and $f$, it follows easily from Lemma 3.2 that $T$ maps $\Omega$ into itself. To finish the proof, we only need to show that $T$ is a contraction. Indeed, for $u, v \in \Omega$, by (3.4), we have

$$
\begin{aligned}
\left|(T u(t))_{i}-(T v(t))_{i}\right| & \\
= & \mid \int_{0}^{1} G_{i}(t, q s)\left(f_{i}\left(s, u_{i}\left(\tau_{i 1}(s)\right), \ldots, u_{N}\left(\tau_{i N}(s)\right)\right) d_{q} s\right. \\
& \left.-f_{i}\left(s, v_{1}\left(\tau_{i 1}(s)\right), \ldots, v_{N}\left(\tau_{i N}(s)\right)\right)\right) d_{q} s \mid \\
\leq & \int_{0}^{1} G_{i}(t, q s) \mid f_{i}\left(s, u_{i}\left(\tau_{i 1}(s)\right), \ldots, u_{N}\left(\tau_{i N}(s)\right)\right) d_{q} s \\
& -f_{i}\left(t, v_{1}\left(\tau_{i 1}(t)\right), \ldots, v_{N}\left(\tau_{i N}(t)\right)\right) \mid d_{q} s \\
\leq & \int_{0}^{1} G_{i}(t, q s)\left(\sum_{j=1}^{N} \lambda_{i j}(t)\left|u_{j}\left(\tau_{i j}(s)\right)-v_{j}\left(\tau_{i j}(s)\right)\right|\right) d_{q} s .
\end{aligned}
$$

This, combined with Theorem 2.6 and (3.5), immediately implies that $T: \Omega \rightarrow \Omega$ is a contraction. Therefore, the proof is complete with the help of Lemma 3.1 and Theorem 2.6.

The following result can be proved in the same spirit as that for Theorem 3.3. 
Theorem 3.4 Suppose that there exist functions $\lambda_{i}(t) \in C\left([0,1], \mathbb{R}_{+}\right), i, j=1,2, \ldots, N$, and nonnegative constants $p_{i 1}, p_{i 2}, \ldots, p_{i N}$ such that $\sum_{j=1}^{N} p_{i j}=1$ and

$$
\left|f_{i}\left(t, u_{1}, \ldots, u_{N}\right)-f_{i}\left(t, v_{1}, \ldots, v_{N}\right)\right| \leq \lambda_{i}(t) \prod_{j=1}^{N}\left|u_{j}-v_{j}\right|^{p_{i j}}
$$

for $t \in[0,1],\left(u_{1}, u_{2}, \ldots, u_{N}\right)^{T},\left(v_{1}, v_{2}, \ldots, v_{N}\right)^{T} \in \mathbb{R}_{+}^{N}$. If

$$
\max _{1 \leq i \leq N} \int_{0}^{1} G_{i}(1, q s) \lambda_{i}(s) d_{q} s<1
$$

then (1.1) has a unique positive solution.

Theorem 3.5 Suppose that there exist nonnegative real-valued functions $m_{i}, n_{i 1}, \ldots, n_{i N} \in$ $L[0,1], i, j=1,2, \ldots, N$, such that

$$
f_{i}\left(t, u_{1}, \ldots, u_{N}\right) \leq m_{i}(t)+\sum_{j=1}^{N} n_{i j}(t) u_{j}
$$

for almost every $t \in[0,1]$ and all $\left(u_{1}, u_{2}, \ldots, u_{N}\right)^{T} \in \mathbb{R}_{+}^{N}$. If

$$
\max _{1 \leq i \leq N} \int_{0}^{1} G_{i}(1, q s)\left(\sum_{j=1}^{N} n_{i j}(s)\right) d_{q} s<1
$$

then (1.1) has at least one positive solution.

Proof Let $\Omega$ and $T: \Omega \rightarrow \Omega$ be defined by (3.6) and (3.7), respectively. We first show that $T$ is completely continuous through the following three steps.

Step 1. Show that $T: \Omega \rightarrow \Omega$ is continuous. Let $\left\{u^{k}(t)\right\}$ be a sequence in $\Omega$ such that $u^{k}(t) \rightarrow u(t) \in \Omega$. Then $\Omega_{0}=[0,1] \times\left\{u(t) \mid u^{k}(t) \in \Omega, t \in[0,1], k \geq 1\right\}$ is bounded in $[0,1] \times$ $\mathbb{R}_{+}^{N}$. Since $f$ is continuous, it is uniformly continuous on any compact set. In particular, for any $\varepsilon>0$, there exists a positive integer $K_{0}$ such that

$$
\begin{aligned}
& \left|f_{i}\left(t, u_{1}^{k}\left(\tau_{i 1}(t)\right), \ldots, u_{N}^{k}\left(\tau_{i N}(t)\right)\right)-f_{i}\left(t, u_{1}\left(\tau_{i 1}(t)\right), \ldots, u_{N}\left(\tau_{i N}(t)\right)\right)\right| \\
& \quad<\frac{\varepsilon}{\max _{1 \leq i \leq N} \max _{t \in[0,1]} \int_{0}^{1} G_{i}(t, q s) d_{q} s},
\end{aligned}
$$

for $t \in[0,1]$ and $k \geq K_{0}, i=1,2, \ldots, N$. Then, for $t \in[0,1]$ and $k \geq K_{0}, i=1,2, \ldots, N$, we have

$$
\begin{aligned}
\left|\left(T u^{k}(t)\right)_{i}-(T u(t))_{i}\right| & \\
= & \mid \int_{0}^{1} G_{i}(t, q s)\left(f_{i}\left(s, u_{1}^{k}\left(\tau_{i 1}(s)\right), \ldots, u_{N}^{k}\left(\tau_{i N}(s)\right)\right)\right. \\
& \left.\quad-f_{i}\left(s, u_{1}\left(\tau_{i 1}(s)\right), \ldots, u_{N}\left(\tau_{i N}(s)\right)\right)\right) d_{q} s \mid \\
\quad \leq & \int_{0}^{1} G_{i}(t, q s) \mid f_{i}\left(s, u_{1}^{k}\left(\tau_{i 1}(s)\right), \ldots, u_{N}^{k}\left(\tau_{i N}(s)\right)\right)
\end{aligned}
$$




$$
\begin{aligned}
& -f_{i}\left(s, u_{1}\left(\tau_{i 1}(s)\right), \ldots, u_{N}\left(\tau_{i N}(s)\right)\right) \mid d_{q} s \\
\leq & \frac{\varepsilon}{\max _{1 \leq i \leq N} \max _{t \in[0,1]} \int_{0}^{1} G_{i}(t, q s) d_{q} s} \int_{0}^{1} G_{i}(t, q s) d_{q} s \leq \varepsilon .
\end{aligned}
$$

Therefore, $\left\|T u^{k}(t)-T u(t)\right\| \leq \varepsilon$ for $k \geq K_{0}$, which implies that $T$ is continuous.

Step 2. Show that $T$ maps bounded sets of $\Omega$ into bounded sets. Let $A$ be a bounded subset of $\Omega$. Then $[0,1] \times\{u(t) \mid t \in[0,1], u \in A\} \subseteq[0,1] \times \mathbb{R}_{+}^{N}$ is bounded. Since $f$ is continuous, there exists an $M>0$ such that

$$
f_{i}\left(t, u_{1}\left(\tau_{i 1}(t)\right), \ldots, u_{N}\left(\tau_{i N}(t)\right)\right) \leq M, \quad \text { for } u \in A, t \in[0,1], 1 \leq i \leq N
$$

It follows that, for $u \in A, t \in[0,1]$ and $1 \leq i \leq N$,

$$
\begin{aligned}
(T u(t))_{i} & =\int_{0}^{1} G_{i}(t, q s) f_{i}\left(s, u_{1}\left(\tau_{i 1}(s)\right), \ldots, u_{N}\left(\tau_{i N}(s)\right)\right) d_{q} s+\frac{\eta_{i} t^{\alpha_{i}-1}}{\left[\alpha_{i}-1\right]_{q} \cdots\left[\alpha_{i}-n_{i}+1\right]_{q}} \\
& \leq M \int_{0}^{1} G_{i}(t, q s) d_{q} s+\frac{\eta_{i}}{\left[\alpha_{i}-1\right]_{q} \cdots\left[\alpha_{i}-n_{i}+1\right]_{q}} \\
& \leq \max _{1 \leq i \leq M}\left(M \max _{t \in[0,1]} \int_{0}^{1} G_{i}(t, q s) d_{q} s+\frac{\eta_{i}}{\left[\alpha_{i}-1\right]_{q} \cdots\left[\alpha_{i}-n_{i}+1\right]_{q}}\right) .
\end{aligned}
$$

Immediately, we can easily see that $T A$ is a bounded subset of $\Omega$.

Step 3. Show that $T$ maps bounded sets of $\Omega$ into equicontinuous sets. Let $B$ be a bounded subset of $\Omega$. Similarly as in Step 2, there exists $L>0$ such that

$$
f_{i}\left(t, u_{1}\left(\tau_{i 1}(t)\right), \ldots, u_{N}\left(\tau_{i N}(t)\right)\right) \leq L, \quad \text { for } u \in B, t \in[0,1], 1 \leq i \leq N
$$

Then, for any $u \in B$ and $t_{1}, t_{2} \in[0,1]$ and $1 \leq i \leq N$,

$$
\begin{aligned}
& \left|\left(T u\left(t_{2}\right)\right)_{i}-\left(T u\left(t_{1}\right)\right)_{i}\right| \\
& =\mid \int_{0}^{1}\left(G_{i}\left(t_{2}, q s\right)-G_{i}\left(t_{1}, q s\right)\right) f_{i}\left(s, u_{1}\left(\tau_{i 1}(s)\right), \ldots, u_{N}\left(\tau_{i N}(s)\right)\right) d_{q} s \\
& \quad+\frac{\eta_{i}\left(t_{2}^{\alpha_{i}-1}-t_{1}^{\alpha_{i}-1}\right)}{\left[\alpha_{i}-1\right]_{q} \cdots\left[\alpha_{i}-n_{i}+1\right]_{q}} \mid \\
& \quad \leq \int_{0}^{1}\left|G_{i}\left(t_{2}, q s\right)-G_{i}\left(t_{1}, q s\right)\right| L d_{q} s+\frac{\eta_{i}\left|t_{2}^{\alpha_{i}-1}-t_{1}^{\alpha_{i}-1}\right|}{\left[\alpha_{i}-1\right]_{q} \cdots\left[\alpha_{i}-n_{i}+1\right]_{q}} \\
& \quad \leq \max _{s \in[0,1]}\left|G_{i}\left(t_{2}, q s\right)-G_{i}\left(t_{1}, q s\right)\right| L+\frac{\eta_{i}\left|t_{2}^{\alpha_{i}-1}-t_{1}^{\alpha_{i}-1}\right|}{\left[\alpha_{i}-1\right]_{q} \cdots\left[\alpha_{i}-n_{i}+1\right]_{q}} .
\end{aligned}
$$

Now the equicontinuity of $T$ on $B$ follows easily from the fact that $G_{i}$ is continuous and hence uniformly continuous on $[0,1] \times[0,1]$.

Now we have shown that $T$ is completely continuous. To apply Theorem 2.7 , let

$$
\mu=\frac{\max _{1 \leq i \leq N}\left\{\int_{0}^{1} G_{i}(1, q s) m_{i}(s) d_{q} s+\eta_{i} /\left[\alpha_{i}-1\right]_{q} \cdots\left[\alpha_{i}-n_{i}+1\right]_{q}\right\}}{1-\max _{1 \leq i \leq N}\left\{\int_{0}^{1} G_{i}(1, q s)\left(\sum_{j=1}^{N} n_{i j}(s)\right) d_{q} s\right\}} .
$$


Fix $r>\mu$ and define $U=\{u \in \Omega:\|u\|<r\}$. We claim that there is no $u \in U$ such that $u=\lambda T u$ for some $\lambda \in(0,1)$. Otherwise, assume that there exist $\lambda \in(0,1)$ and $u \in \partial U$ such that $u=\lambda T u$. Then

$$
\begin{aligned}
\left|u_{i}(t)\right|= & \left|\lambda(T u(t))_{i}\right| \leq\left|(T u(t))_{i}\right| \\
= & \int_{0}^{1} G_{i}(t, q s) f_{i}\left(s, u_{1}\left(\tau_{i 1}(s)\right), \ldots, u_{N}\left(\tau_{i N}(s)\right)\right) d_{q} s+\frac{\eta_{i} t^{\alpha_{i}-1}}{\left[\alpha_{i}-1\right]_{q} \cdots\left[\alpha_{i}-n_{i}+1\right]_{q}} \\
\leq & \int_{0}^{1} G_{i}(t, q s)\left(m_{i}(s)+\sum_{j=1}^{N} n_{i j}(s) u_{j}\left(\tau_{i j}(s)\right)\right) d_{q} s+\frac{\eta_{i}}{\left[\alpha_{i}-1\right]_{q} \cdots\left[\alpha_{i}-n_{i}+1\right]_{q}} \\
\leq & \int_{0}^{1} G_{i}(t, q s) m_{i}(s) d_{q} s+r \int_{0}^{1} G_{i}(t, q s)\left(\sum_{j=1}^{N} n_{i j}(s)\right) d_{q} s \\
& +\frac{\eta_{i}}{\left[\alpha_{i}-1\right]_{q} \cdots\left[\alpha_{i}-n_{i}+1\right]_{q}} \\
< & \int_{0}^{1} G_{i}(1, q s) m_{i}(s) d_{q} s+\frac{\eta_{i}}{\left[\alpha_{i}-1\right]_{q} \cdots\left[\alpha_{i}-n_{i}+1\right]_{q}} \\
& +r \int_{0}^{1} G_{i}(1, q s)\left(\sum_{j=1}^{N} n_{i j}(s)\right) d_{q} s \\
\leq & \mu\left(1-\max _{1 \leq i \leq N}\left\{\int_{0}^{1} G_{i}(1, q s)\left(\sum_{j=1}^{N} n_{i j}(s)\right) d_{q} s\right\}\right)+r \int_{0}^{1} G_{i}(1, q s)\left(\sum_{j=1}^{N} n_{i j}(s)\right) d_{q} s \\
< & r\left(1-\max _{1 \leq i \leq N}\left\{\int_{0}^{1} G_{i}(1, q s)\left(\sum_{j=1}^{N} n_{i j}(s)\right) d_{q} s\right\}\right) \\
& +r \int_{0}^{1} G_{i}(1, q s)\left(\sum_{j=1}^{N} n_{i j}(s)\right) d_{q} s \leq r . \\
& (1, y)
\end{aligned}
$$

Therefore, $\|u\|<r$, a contradiction to $u \in \partial U$. This proves the claim. Applying Theorem 2.7, we know that $T$ has a fixed point in $\bar{U}$, which is a positive solution to (1.1) by Lemma 3.1. Therefore, the proof is complete.

Corollary 3.6 If all $f_{i}, i, j=1,2, \ldots, N$, are bounded, then (1.1) has at least one positive solution.

To state the last result of this section, we introduce

$$
M_{1}=\left(\max _{1 \leq i \leq N} \int_{0}^{1} G_{i}(1, q s) d_{q} s\right)^{-1}
$$

Theorem 3.7 Suppose that there exist $M_{2} \in\left(0, M_{1}\right)$ and positive constants $0<r_{1}<r_{2}$ with $r_{2} \geq \max _{1 \leq i \leq N}\left\{\eta_{i} /\left[\alpha_{i}-1\right]_{q} \cdots\left[\alpha_{i}-n_{i}+1\right]_{q}\right\} /\left(1-M_{2} / M_{1}\right)$ such that

(a) $f_{i}\left(t, u_{1}, \ldots, u_{N}\right) \leq M_{2} r_{2}$ for $\left(t, u_{1}, \ldots, u_{N}\right) \in[0,1] \times B_{r_{2}}, i=1,2, \ldots, N$, and

(b) $f_{i}\left(t, u_{1}, \ldots, u_{N}\right) \geq M_{1} r_{1}$ for $\left(t, u_{1}, \ldots, u_{N}\right) \in[0,1] \times B_{r_{1}}, i=1,2, \ldots, N$, where $B_{r_{i}}=\left\{u=\left(u_{1}, \ldots, u_{N}\right)^{T} \in \mathbb{R}_{+}^{N} \mid \max _{1 \leq i \leq N} u_{i} \leq r_{i}\right\}, i=1,2$. Then (1.1) has at least a positive solution. 
Proof Let $\Omega$ be defined by (3.5) and $\Omega_{i}=\left\{u \in E \mid\|u\|<r_{i}\right\}, i=1,2$. Obviously, $\Omega$ is a cone in $E$. From the proof of Theorem 3.5, we know that the operator $T$ defined by (3.6) is completely continuous on $\Omega$. For any $u \in \Omega \cap \partial \Omega_{1}$, it follows from Theorem 2.8 and condition (b) that

$$
\begin{aligned}
\|T u\|_{E}= & \max _{1 \leq i \leq N} \max _{0 \leq t \leq 1}(\operatorname{Tu}(t))_{i} \geq \max _{1 \leq i \leq N}(\operatorname{Tu}(1))_{i} \\
= & \max _{1 \leq i \leq N}\left\{\int_{0}^{1} G_{i}(1, q s) f_{i}\left(s, u_{1}\left(\tau_{i 1}(s)\right), \ldots, u_{N}\left(\tau_{i N}(s)\right)\right) d_{q} s\right. \\
& \left.+\frac{\eta_{i}}{\left[\alpha_{i}-1\right]_{q} \cdots\left[\alpha_{i}-n_{i}+1\right]_{q}}\right\} \\
\geq & \max _{1 \leq i \leq N}\left\{\int_{0}^{1} G_{i}(1, q s) d_{q} s M_{1} r_{1}+\frac{\eta_{i}}{\left[\alpha_{i}-1\right]_{q} \cdots\left[\alpha_{i}-n_{i}+1\right]_{q}}\right\} \geq r_{1}=\|u\|_{E},
\end{aligned}
$$

that is, $\|T u\|_{E} \geq\|u\|_{E}$ for $u \in \Omega \cap \partial \Omega_{1}$.

On the other hand, for any $u \in \Omega \cap \partial \Omega_{2}$, it follows from Lemma 3.2 and condition (a) that, for $t \in[0,1]$,

$$
\begin{aligned}
(\operatorname{Tu}(t))_{i} & \leq \max _{1 \leq i \leq N} \int_{0}^{1} G_{i}(1, q s) d_{q} s M_{2} r_{2}+\max _{1 \leq i \leq N} \frac{\eta_{i}}{\left[\alpha_{i}-1\right]_{q} \cdots\left[\alpha_{i}-n_{i}+1\right]_{q}} \\
& \leq \max _{1 \leq i \leq N} \int_{0}^{1} G_{i}(1, q s) d_{q} s M_{2} r_{2}+\left(1-M_{2} / M_{1}\right) r_{2} \leq r_{2}=\|u\|_{E}
\end{aligned}
$$

that is, $\|T u\|_{E} \leq\|u\|_{E}$ for $u \in \Omega \cap \partial \Omega_{2}$. Therefore, we have verified condition (b) of Theorem 2.8. It follows that $T$ has a fixed point in $\Omega \cap\left(\bar{\Omega}_{2} \backslash \Omega_{1}\right)$, which is a positive solution to (1.1). This completes the proof.

\section{Some examples}

In this section, we demonstrate the feasibility of some of the results obtained in Section 3.

Example 4.1 Consider the following fractional $q$-difference system:

$$
\begin{aligned}
& \left(D_{0.5}^{2.5} x_{1}\right)(t)+\frac{e^{-t}\left(x_{1}(t / 2)+x_{2}(\sin t)\right)}{\left(1+e^{t}\right)\left(1+x_{1}(t / 2)+x_{2}(\sin t)\right)}=0, \quad t \in(0,1), \\
& \left(D_{0.5}^{2.5} x_{2}\right)(t)+\frac{e^{t}\left(x_{1}\left(t^{2}\right)+x_{2}(\sin t)\right)}{2\left(1+x_{1}\left(t^{2}\right)+x_{2}(\sin t)\right)}=0, \quad t \in(0,1), \\
& x_{1}(0)=x_{2}(0)=\left(D_{0.5} x_{1}\right)(0)=\left(D_{0.5} x_{2}\right)(0)=0, \quad\left(D_{0.5}^{2} x_{1}\right)(1)=\left(D_{0.5}^{2} x_{2}\right)(1)=\frac{1}{2} .
\end{aligned}
$$

Here $n_{1}=n_{2}=3, \alpha_{1}=\alpha_{2}=2.5, q=\eta_{1}=\eta_{2}=0.5, \tau_{11}(t)=t / 2, \tau_{12}(t)=\tau_{22}(t)=\sin t$, $\tau_{21}(t)=t^{2}$

$$
f_{1}\left(t, x_{1}, x_{2}\right)=\frac{e^{-t}\left(x_{1}+x_{2}\right)}{\left(1+e^{t}\right)\left(1+x_{1}+x_{2}\right)}, \quad f_{1}\left(t, x_{1}, x_{2}\right)=\frac{e^{t}\left(x_{1}+x_{2}\right)}{2\left(1+x_{1}+x_{2}\right)}
$$

One can easily see that (3.4) is satisfied with

$$
\lambda_{11}(t)=\lambda_{12}(t)=\frac{e^{-t}}{1+e^{t}}, \quad \lambda_{21}(t)=\lambda_{22}(t)=\frac{t^{2}}{2} .
$$


Moreover,

$$
G_{1}(1, s)=G_{2}(1, s)=\frac{(1-s)^{(-0.5)}-(1-s)^{(1.5)}}{\Gamma_{0.5}(2.5)}, \quad 0 \leq s \leq 1
$$

and hence [27]

$$
\begin{aligned}
\max _{1 \leq i \leq 2} \int_{0}^{1} G_{i}(1, q s)\left(\sum_{j=1}^{2} \lambda_{i j}(s)\right) d_{q} s & \leq \int_{0}^{1} G_{i}(1, q s) \max _{0 \leq s \leq 1}\left\{s^{2}, \frac{2}{e^{s}\left(1+e^{s}\right)}\right\} d_{q} s \\
& \leq \int_{0}^{1} G_{i}(1, q s) d_{q} s \leq 0.48636 .
\end{aligned}
$$

It follows from Theorem 3.3 that (4.1) has a unique positive solution on $[0,1]$.

Example 4.2 Consider the following fractional $q$-difference system:

$$
\begin{aligned}
& \left(D_{0.5}^{2.5} x_{1}\right)(t)+\frac{t x_{1}(t)}{2}+\frac{x_{2}(t)}{2}+\frac{t}{3}+\frac{1}{3}=0, \quad t \in(0,1), \\
& \left(D_{0.5}^{2.5} x_{2}\right)(t)+\frac{x_{1}(t)}{2}+\frac{t x_{2}(t)}{2}+\frac{t^{2}}{3}+\frac{1}{3}=0, \quad t \in(0,1), \\
& x_{1}(0)=x_{2}(0)=\left(D_{0.5} x_{1}\right)(0)=\left(D_{0.5} x_{2}\right)(0)=0, \quad\left(D_{0.5}^{2} x_{1}\right)(1)=\left(D_{0.5}^{2} x_{2}\right)(1)=\frac{1}{2} .
\end{aligned}
$$

Here $n_{1}=n_{2}=3, \alpha_{1}=\alpha_{2}=2.5, q=\eta_{1}=\eta_{2}=0.5, \eta_{1}=\eta_{2}=1 / 2$,

$$
f_{i}\left(t, x_{1}, x_{2}\right)=m_{i}(t)+\sum_{j=1}^{2} n_{i j} x_{j}, \quad i=1,2,
$$

where

$$
m_{1}(t)=\frac{t}{3}+\frac{1}{3}, \quad m_{2}(t)=\frac{t^{2}}{3}+\frac{1}{3}, \quad n_{11}(t)=n_{22}(t)=\frac{t}{2}, \quad n_{12}(t)=n_{21}(t)=\frac{1}{2} .
$$

One can easily see that (3.8) is satisfied. Moreover,

$$
G_{1}(1, s)=G_{2}(1, s)=\frac{(1-s)^{(-0.5)}-(1-s)^{(1.5)}}{\Gamma_{0.5}(2.5)}, \quad 0 \leq s \leq 1
$$

and hence [27]

$$
\begin{aligned}
\max _{1 \leq i \leq 2} \int_{0}^{1} G_{i}(1, q s)\left(\sum_{j=1}^{2} n_{i j}(s)\right) d_{q} s & \leq \int_{0}^{1} G_{i}(1, q s) \max _{0 \leq s \leq 1}\left\{\frac{s+1}{2}\right\} d_{q} s \\
& \leq \int_{0}^{1} G_{i}(1, q s) d_{q} s \leq 0.48636 .
\end{aligned}
$$

It follows from Theorem 3.5 that (4.2) has at least one positive solution on $[0,1]$. 


\section{Competing interests}

The authors declare that they have no competing interests.

\section{Authors' contributions}

The authors contributed to each part of this work equally and read and approved the final version of the manuscript.

\section{Acknowledgements}

The authors sincerely thank the editor and reviewers for their valuable suggestions and useful comments that have led to the present improved version of the original manuscript.

Received: 18 October 2013 Accepted: 14 January 2014 Published: 31 Jan 2014

\section{References}

1. Agarwal, RP, Ahmad, B: Existence theory for anti-periodic boundary value problems of fractional differential equations and inclusions. Comput. Math. Appl. 62, 1200-1214 (2011)

2. Agarwal, RP, O'Regan, D, Staněk, S: Positive solutions for Dirichlet problems of singular nonlinear fractional differential equations. J. Math. Anal. Appl. 371, 57-68 (2010)

3. Agarwal, RP, Lakshmikantham, V, Nieto, JJ: On the concept of solution for fractional differential equations with uncertainty. Nonlinear Anal. 72, 2859-2862 (2010)

4. Ahmad, B, Nieto, JJ, Pimentel, J: Some boundary value problems of fractional differential equations and inclusions. Comput. Math. Appl. 62, 1238-1250 (2011)

5. Ahmad, B, Nieto, Jj: Existence results for nonlinear boundary value problems of fractional integrodifferential equations with integral boundary conditions. Bound. Value Probl. 2009, Article ID 708576 (2009)

6. Ahmad, B, Ntouyas, S, Assolami, A: Caputo type fractional differential equations with nonlocal Riemann-Liouville integral boundary conditions. J. Appl. Math. Comput. (2013). doi:10.1007/s12190-012-0610-8

7. Ouyang, Z, Chen, Y, Zou, S: Existence of positive solutions to a boundary value problem for a delayed nonlinear fractional differential system. Bound. Value Probl. 2011, Article ID 475126 (2011)

8. Jackson, FH: On q-functions and a certain difference operator. Trans. R. Soc. Edinb. 46, 253-281 (1908)

9. Jackson, FH: On q-definite integrals. Q. J. Pure Appl. Math. 41, 193-203 (1910)

10. Kac, V, Cheung, P, Quantum Calculus. Springer, New York (2002)

11. Al-Salam, WA: Some fractional $q$-integrals and q-derivatives. Proc. Edinb. Math. Soc. 15(2), 135-140 (1966/1967)

12. Agarwal, RP: Certain fractional $q$-integrals and q-derivatives. Proc. Camb. Philos. Soc. 66, 365-370 (1969)

13. Abdeljawad, T, Benli, B, Baleanu, D: A generalized $q$-Mittag-Leffler function by $q$-Caputo fractional linear equations. Abstr. Appl. Anal. 2012, Article ID 546062 (2012)

14. Rajković, PM, Marinković, SD, Stanković, MS: On q-analogues of Caputo derivative and Mittag-Leffler function. Fract. Calc. Appl. Anal. 10, 359-373 (2007)

15. Rajković, PM, Marinković, SD, Stanković, MS: Fractional integrals and derivatives in $q$-calculus. Appl. Anal. Discrete Math. 1, 311-323 (2007)

16. Atici, FM, Eloe, PW: Fractional q-calculus on a time scale. J. Nonlinear Math. Phys. 14, 333-344 (2007)

17. El-Shahed, M, Al-Askar, FM: On the existence and uniqueness of solutions for $q$-fractional boundary value problem. Int. J. Math. Anal. 5, 1619-1630 (2011)

18. Zhao, Y, Chen, H, Zhang, Q: Existence results for fractional q-difference equations with nonlocal $q$-integral boundary conditions. Adv. Differ. Equ. 2013, Article ID 48 (2013)

19. Zhao, Y, Chen, $H$, Zhang, Q: Existence and multiplicity of positive solutions for nonhomogeneous boundary value problems with fractional q-derivative. Bound. Value Probl. 2013, Article ID 103 (2013)

20. Yang, W: Positive solutions for boundary value problems involving nonlinear fractional $q$-difference equations. Differ. Equ. Appl. 5, 205-219 (2013)

21. Yang, W: Positive solution for fractional $q$-difference boundary value problems with $\phi$-Laplacian operator. Bull. Malays. Math. Soc. 36(4), 1195-1203 (2013)

22. El-Shahed, M, Al-Askar, FM: Positive solutions for boundary value problem of nonlinear fractional $q$-difference equation. ISRN Math. Anal. 2011, Article ID 385459 (2011)

23. Graef, JR, Kong, L: Positive solutions for a class of higher order boundary value problems with fractional $q$-derivatives. Appl. Math. Comput. 218, 9682-9689 (2012)

24. $\mathrm{Ma}$, J, Yang, J: Existence of solutions for multi-point boundary value problem of fractional $q$-difference equation. Electron. J. Qual. Theory Differ. Equ. 92, 1-10 (2011)

25. Zhao, Y, Ye, G, Chen, H: Multiple positive solutions of a singular semipositone integral boundary value problem for fractional q-derivatives equation. Abstr. Appl. Anal. 2013, Article ID 643571 (2013)

26. Ferreira, RAC: Nontrivial solutions for fractional $q$-difference boundary value problems. Electron. J. Qual. Theory Differ. Equ. 70, 1-10 (2010)

27. Ferreira, RAC: Positive solutions for a class of boundary value problems with fractional $q$-differences. Comput. Math. Appl. 61, 367-373 (2011)

28. Liang, S, Zhang, J: Existence and uniqueness of positive solutions for three-point boundary value problem with fractional q-differences. J. Appl. Math. Comput. 40, 277-288 (2012)

29. Ahmad, B, Ntouyas, S, Purnaras, I: Existence results for nonlocal boundary value problems of nonlinear fractional q-difference equations. Adv. Differ. Equ. 2012, Article ID 140 (2012)

30. Alsaedi, A, Ahmad, B, Al-Hutami, H: A study of nonlinear fractional q-difference equations with nonlocal integral boundary conditions. Abstr. Appl. Anal. 2013, Article ID 410505 (2013)

31. Agarwal, RP, Meehan, M, O'Regan, D: Fixed Point Theory and Applications. Cambridge Tracts in Mathematics, vol. 141. Cambridge University Press, Cambridge (2001)

32. Li, C, Luo, X, Zhou, Y: Existence of positive solutions of the boundary value problem for nonlinear fractional differential equations. Comput. Math. Appl. 59, 1363-1375 (2010)

33. Granas, A, Guenther, RB, Lee, JW: Some general existence principles in the Carathéodory theory of nonlinear differential systems. J. Math. Pures Appl. 70, 153-196 (1991) 
34. Krasnosel'skii, MA: Topological Methods in the Theory of Nonlinear Integral Equations. Macmillan Co., New York (1964)

10.1186/1687-1847-2014-51

Cite this article as: Yuan and Yang: Positive solutions of nonlinear boundary value problems for delayed fractional q-difference systems. Advances in Difference Equations 2014, 2014:51

Submit your manuscript to a SpringerOpen ${ }^{\circ}$ journal and benefit from:

- Convenient online submission

- Rigorous peer review

- Immediate publication on acceptance

- Open access: articles freely available online

- High visibility within the field

- Retaining the copyright to your article

Submit your next manuscript at $>$ springeropen.com 